\title{
Testing of Flexible Ballutes in Hypersonic Wind Tunnels for Planetary Aerocapture
}

\author{
Gregory M. Buck* \\ NASA Langley Research Center, Hampton, Virginia
}

\begin{abstract}
Studies were conducted for the In-Space Propulsion (ISP) Ultralightweight Ballute Technology Development Program to increase the technical readiness level of inflatable decelerator systems for planetary aerocapture. The present experimental study was conducted to develop the capability for testing lightweight, flexible materials in hypersonic facilities. The primary objectives were to evaluate advanced polymer film materials in a high-temperature, high-speed flow environment and provide experimental data for comparisons with fluid-structure interaction modeling tools. Experimental testing was conducted in the Langley Aerothermodynamics Laboratory 20-Inch Hypersonic $\mathrm{CF}_{4}$ and 31Inch Mach 10 Air blowdown wind tunnels. Quantitative flexure measurements were made for 60 degree half angle afterbody-attached ballutes, in which polyimide films (1-mil and 3mil thick) were clamped between a 1/2-inch diameter disk and a base ring (4-inch and 6-inch diameters). Deflection measurements were made using a parallel light silhouette of the film surface through an existing schlieren optical system. The purpose of this paper is to discuss these results as well as free-flying testing techniques being developed for both an afterbodyattached and trailing toroidal ballute configuration to determine dynamic fluid-structural stability. Methods for measuring polymer film temperature were also explored using both temperature sensitive paints (for up to $370 \mathrm{C}$ ) and laser-etched thin-film gages.
\end{abstract}

Key words: Ballute, Aerocapture, Hypersonic, Deflections, Stability.

\section{Nomenclature}

$\mathrm{CF}_{4} \quad=$ fluoromethane (test gas used in the Langley Research Center 20-Inch Hypersonic $\mathrm{CF}_{4}$ Tunnel)

$K n_{L} \quad=$ freestream Knudsen number based on vehicle length

$L \quad=$ Body length parameter

$M_{l} \quad=$ freestream Mach number

$P_{T, 1} \quad=$ stagnation pressure

$P_{T, 2} \quad=$ post-normal-shock stagnation pressure, or pitot pressure

$\operatorname{Re}_{L} \quad=$ freestream Reynolds number based on vehicle length

$\operatorname{Re}_{1} \quad=$ unit freestream Reynolds number

$\gamma \quad=\quad$ ratio of specific heats

\section{Introduction}

Studies are being conducted for the In-Space Propulsion (ISP) Ultralightweight Ballute Technology Development Program at NASA to increase the technical readiness level of inflatable decelerator systems for planetary aerocapture. A ballute (balloon-parachute) is an inflatable, aerodynamic drag device. Figure 1 shows a family of these inflatable decelerators (trailing ballute, afterbody-attached ballute, forebody-attached inflatable aeroshell) that are being studied.

\footnotetext{
* Aerospace Engineer, Aerothermodynamics Branch, Mail Stop 408A, AIAA Member.
} 

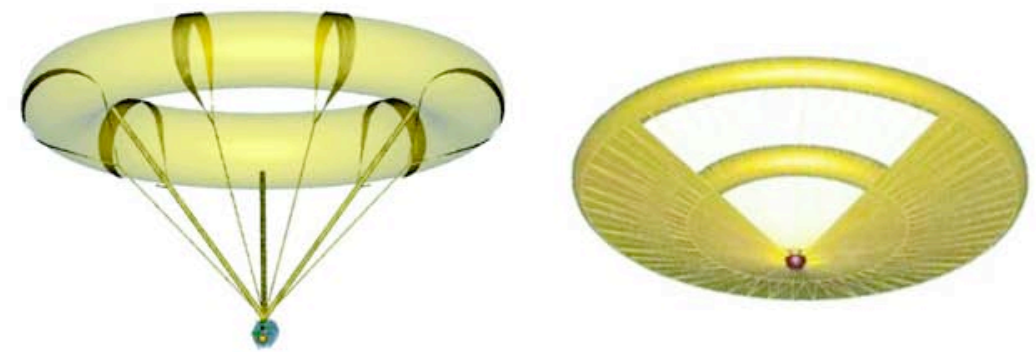

Trailing Ballute*

\section{Afterbody Attached Ballute*}

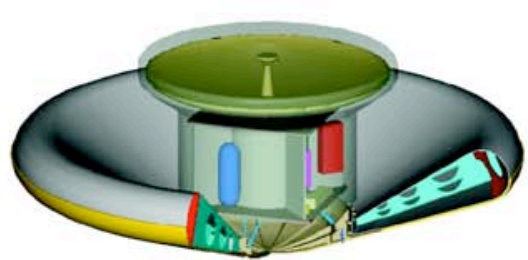

Forebody-Attached
Inflatable Aeroshell
(LMA Study)

${ }^{*}$ Ballute $=$ Balloon + Parachute

\section{Figure 1. Families of Aerocapture Inflatable Decelerators.}

Since inflatable decelerators can be deployed with much larger cross sections, without on-orbit assembly, these concepts provide an efficient modular alternative to rigid aeroshells for planetary aerocapture. ${ }^{1}$ With a larger aerodynamic cross section, the aerocapture trajectory is shifted to much higher altitudes resulting in much lower flow density, lower dynamic pressure and lower heating. Ultralight configurations being considered in the Ball Studies (trailing and afterbody attached ballutes shown in Fig. 1) take full advantage of these reduced loads in the design of inflatable decelerator systems with lightweight polymer film materials. Using these ultralight inflatable materials for aerocapture, the mass of an interplanetary spacecraft can be reduced by as much as 50 percent over an orbital capture system that is completely propulsive. ${ }^{2}$

A major issue in the design and deployment of these systems, however, is prediction of the fluid-structure interactions and trajectories of such lightweight and flexible vehicles at low-density hypersonic conditions. ${ }^{3}$ Also challenging is the ability to validate these tools experimentally, or provide test conditions upon which to build confidence in such tools. For this reason a hypersonic wind-tunnel test program was established with the following objectives: 1) develop methodology and precedence for testing flexible materials in hypersonic facilities; 2) evaluate advanced materials in a high-temperature, high-speed flow environment; and 3) provide experimental data for comparisons with aerothermal-elastic modeling software tools.

\section{Hypersonic Wind-Tunnel Test Facilities}

These tests were run in the Langley Aerothermodynamics Laboratory (LAL) 20-Inch Hypersonic $\mathrm{CF}_{4}$ Tunnel and 31-Inch Mach 10 Air Tunnel. A complete description of these facilities is given by Micol. ${ }^{4}$ A comparison of low-density simulation capabilities in these facilities with an expected flight trajectory for a Titan aerocapture mission $^{5}$ and a rarefied flow facility at the University of Virginia are shown in Figure 2. These show the range in body dimensions and flow conditions for steady freestream flow simulation capabilities compared to flight. In these figures the body length parameter, L, represents the cross-sectional diameter of a trailing toroidal ballute.

Nominal conditions for lowest-density runs in these LAL facilities are shown in Table 1. Flow conditions below stagnation pressure $\left(\mathrm{P}_{\mathrm{T}, 1}\right)$ of 200 psi in Hypersonic $\mathrm{CF}_{4}$ and $\mathrm{P}_{\mathrm{T}, 1}$ of 360 psi in Mach 10 air are not optimum for those facilities with large sidewall boundary layers resulting in non-uniform Mach and density profiles. Lowest Reynolds numbers are obtained in the $\mathrm{CF}_{4}$ tunnel because of its open-jet test section, versus a continuous sidewall test section for the Mach 10 air tunnel. Test times in each facility can be as long as 30 seconds, although 10 seconds was the longest that ballutes were run in the Hypersonic $\mathrm{CF}_{4}$ tunnel and 3 seconds in the Mach 10 Air tunnel. The Mach 6 $\mathrm{CF}_{4}$ tunnel also simulates high-temperature gas chemistry with $\gamma=1.22$, simulating inviscid air flows of Mach 18 or higher in flight. 

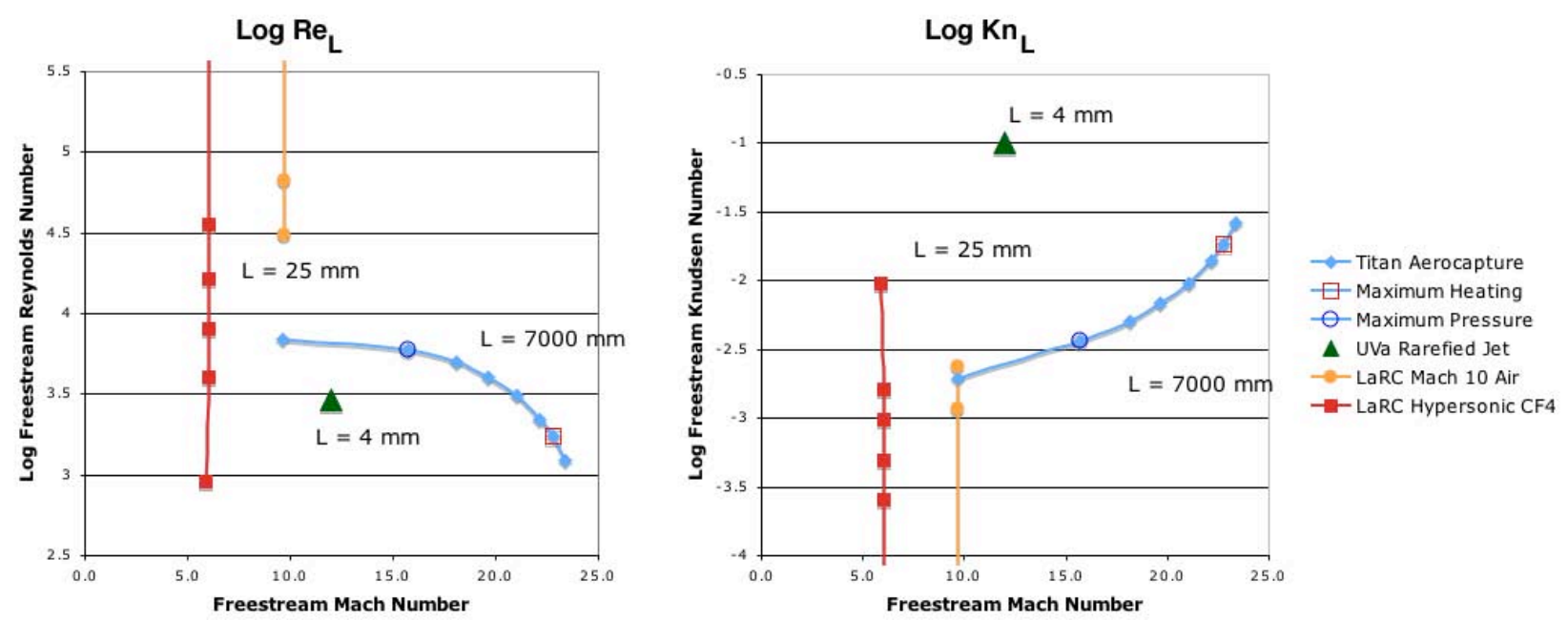

Figure 2. Low-density simulation capabilities of Langley Aerothermodynamic Laboratory (LAL) facilities compared to flight and rarefied flow facility at the University of Virginia.

Actual stagnation temperatures varied from $860^{\circ} \mathrm{F}$ in the $\mathrm{CF}_{4}$ tunnel to $1220^{\circ} \mathrm{F}$ in the Mach 10 air tunnel. These are both higher and lower than nominal conditions respectively and were experienced because the $\mathrm{CF}_{4}$ tunnel had just been outfitted with new in-line heaters and the Mach 10 air tunnel would not reach nominal stagnation temperatures in a reasonable time period with such low mass flows. Actual flow conditions for each run were reduced using the GASPROPS code $^{6}$, using a multi-coefficient virial gas equation of state to determine real gas flow properties. For the test data presented, freestream Reynolds numbers ranged from $25 \mathrm{~K} /$ foot to $120 \mathrm{~K} /$ foot in Hypersonic $\mathrm{CF}_{4}$ and $100 \mathrm{~K} /$ foot to $200 \mathrm{~K} /$ foot in Mach 10 air.

\section{Quantitative Flexture Measurements for Afterbody-Attached Ballutes}

Several wind-tunnel models were built out of a stereolithography (SLA) resin plastic support structure and polyimide membranes to represent an attached ballute concept as shown in Figures 3 through 5. For these models the compression toroid was rigid and constrained normal to the oncoming freestream but was free to move axially. All models in this study were constructed with a $60^{\circ}$ half angle, all of which experienced small fluctuations, but were relatively stable during the runs. Different film thicknesses and cone angles were tested in both hypersonic facilities. Base diameters were 4 and 6-inches. Polyimide film thicknesses tested were 1-mil on the 4-inch diameter and 1 and 3mils on the 6-inch. As shown in the color

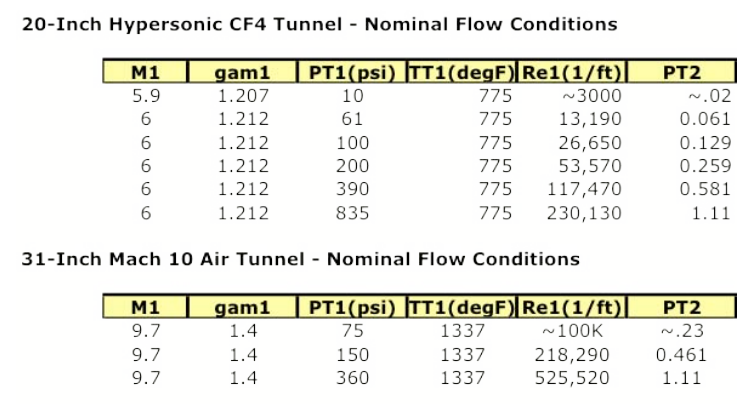

Table 1. LAL low-density flow conditions.

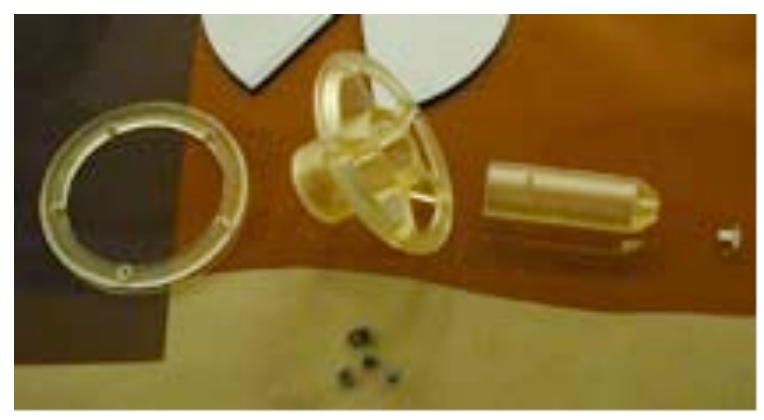

Figure 3. Membrane support structures built from stereolithography resin. 
layer/boundary-layer interactions are coupled with the aeroelastic deformations for each of the different scale models in Hypersonic $\mathrm{CF}_{4}(\mathrm{Re}=$ $120 \mathrm{~K} / \mathrm{ft}$ for both figures). Densities and optical coefficients were too low to measure schlieren shock layers in Mach 10 air. Figures 7 through 10 show digitized film deflections through the schlieren apparatus in each facility. Figure 7 shows aeroelastic deformations measured for a 4inch diameter test model with 1-mil thick polyimide at $\mathrm{Re}=100 \mathrm{~K} / \mathrm{ft}$ and $200 \mathrm{~K} / \mathrm{ft}$ in Mach 10 air. Figures 8 through 10 show aeroelastic deformations for a 4-inch test model with 1-mil thick polyimide and 6-inch test model with 1 and 3 -mil thick polyimide at $\mathrm{Re}=25 \mathrm{~K}$ to $120 \mathrm{~K} / \mathrm{ft}$.

\section{Methods for Measuring Polymer Film Surface Temperature}

Two different measurement techniques were also developed for surface temperature measurements. The first is an array of thin-film resistance sensors that were fabricated directly on the polymer film material. For these tests 2-mil thick polyimide polymer films were used which were uniformly pre-coated with a layer of nickel ( 200 nanometer thick coating). Excess nickel coating was etched off in two steps to form the instrumentation pattern. First, electrical leads to the sensors were formed using a conventional chemical-photo etching process, commonly used for fabricating printed circuit boards. Next, a laser ablation technique was used to etch the sensor patterns. Laser ablation is a critical part of this experimental technique since it produces consistent sensor widths and resistances throughout the instrumentation pattern. This allows for calibration of only a sample of the sensors. This is important since relatively long calibration times at temperatures required $\left(380^{\circ} \mathrm{C}\right)$ destroy the sensors being calibrated. Typical sensor resistance for the sensor pattern used is 150 ohms. Figure 11 shows the instumentation array on an uncut polymer film and close-up of the serpentine sensor pattern.

Most of the resistance elements in the sensor patterns are oriented perpendicular to the radial direction of the film, to reduce the relative effects of strain on the resistance measurements. 4-wire leads were used with a constant current of 1 milliamp across one pair and potential measured across the other to eliminate the effect of strain or temperature on the electrical leads. Figure 12

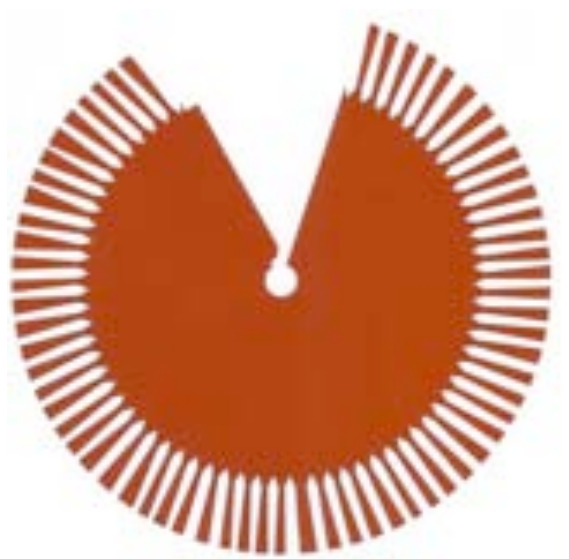

Figure 4. Laser cut polyimide film pattern.

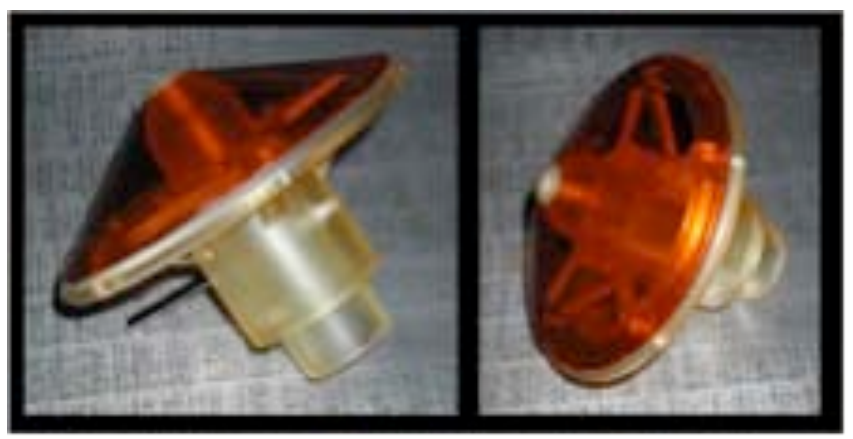

Figure 5. Assembled flexible ballute test model.

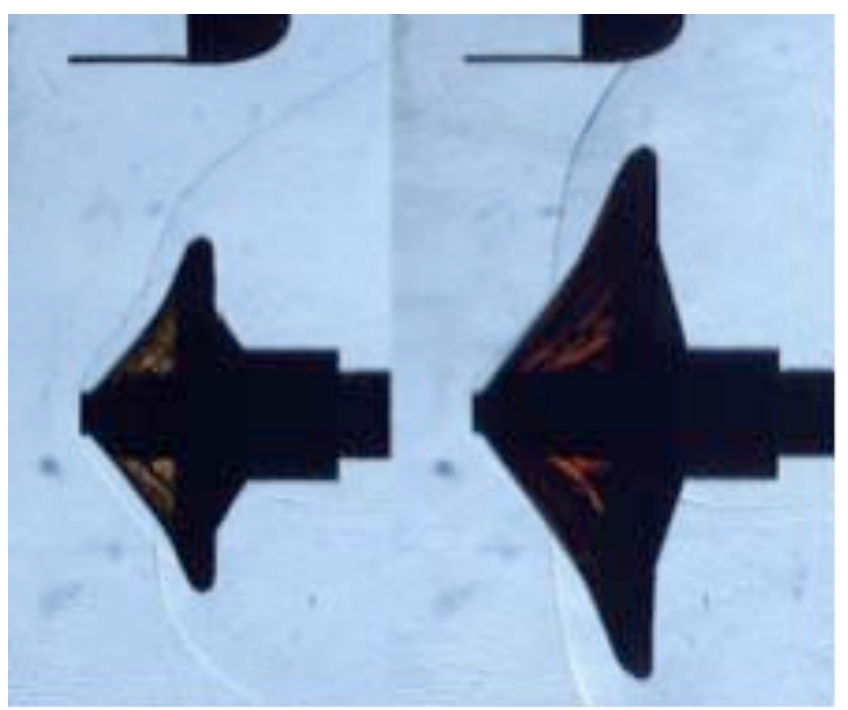

Figure 6. Color schlieren images showing different shocklayer/boundary-layer interactions for 4-inch and 6inch test models in Mach $6 \mathrm{CF}_{4}$. 


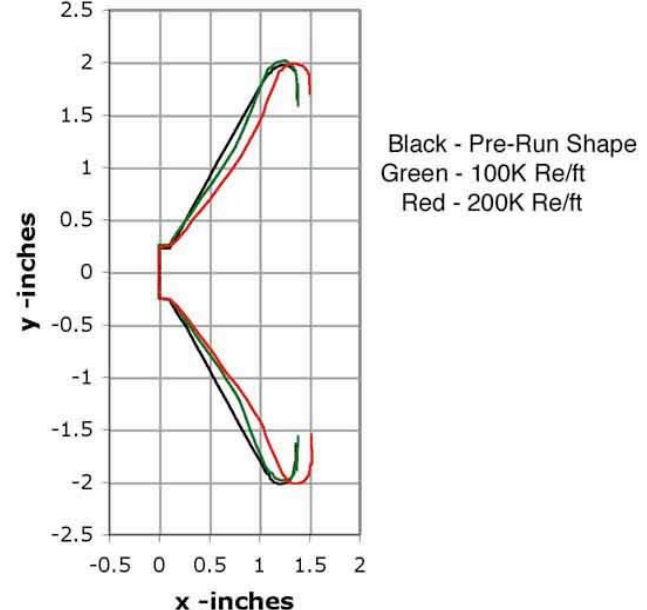

Fig. 7. Aeroelastic deformations for a 4-inch diameter, 1-mil thick polyimide, in Mach 10 air.

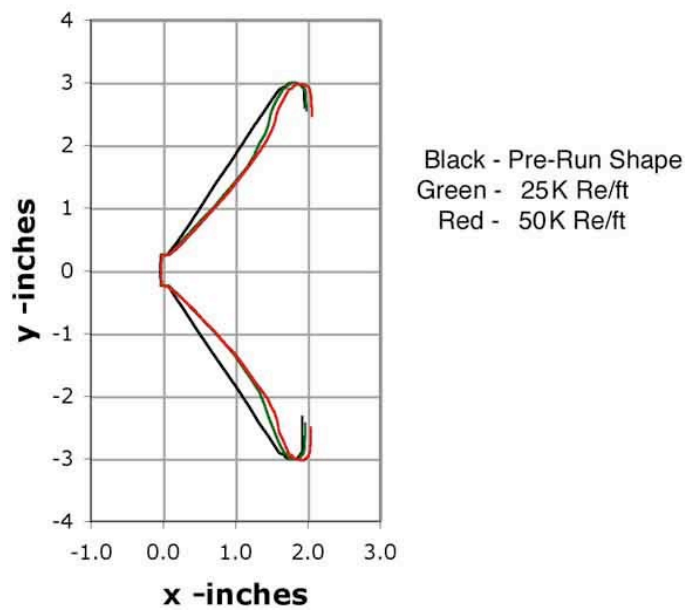

Fig. 9. Aeroelastic deformations for a 6-inch diameter, 1-mil thick polyimide, in Mach 6 CF4.

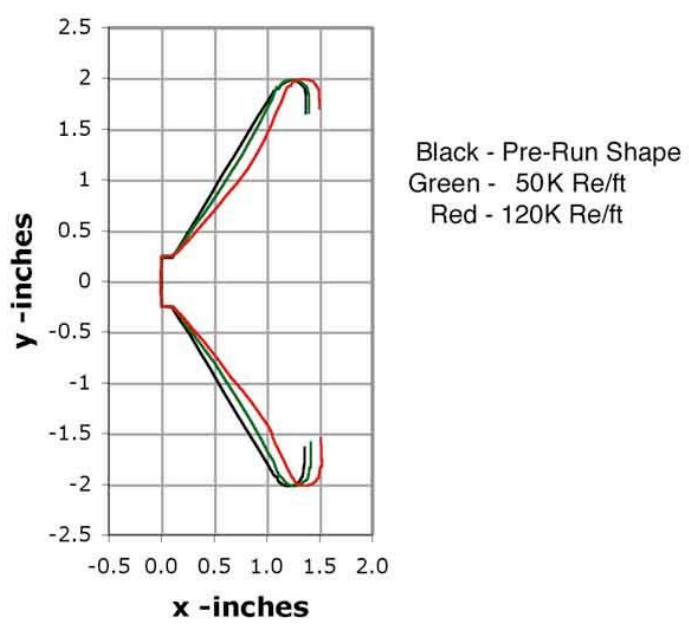

Fig. 8. Aeroelastic deformations for a 4-inch diameter, 1-mil thick polyimide, in Mach $6 \mathrm{CF}_{4}$.

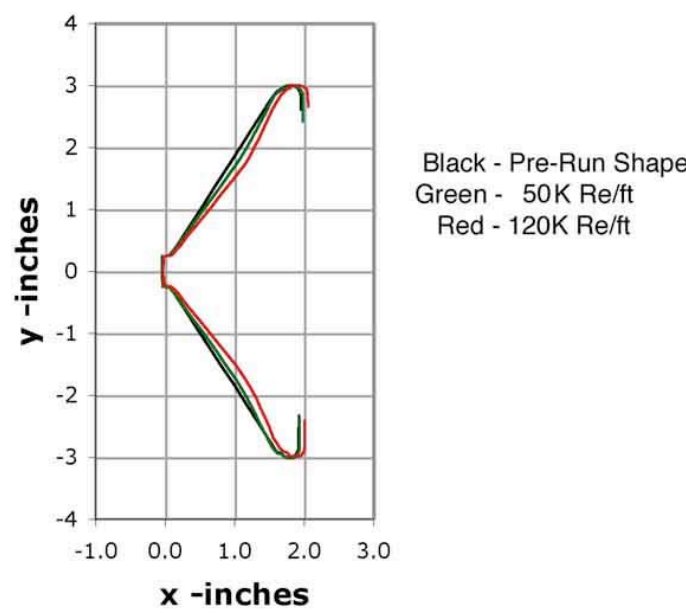

Fig. 10. Aeroelastic deformations for a 6-inch diameter, 3-mil thick polyimide, in Mach 6 CF4.

shows the two models, $60^{\circ}$ and $70^{\circ}$ half-angle afterbody-attached ballutes, which were fabricated and tested. These were both tested in the 31-inch Mach 10 air tunnel at $\mathrm{Re}_{1}=100 \mathrm{~K} / \mathrm{ft}$. Millivolt output measurements are shown in Figure 13 for the $60^{\circ}$ half-angle model. This data shows that sensor number 1 (TV1) which was near the nose of the test model was damaged even before the run. The remaining sensors in the array performed well during the 3-1/2 second run. All but one of the sensors (TV2) were destroyed following the run, during model retraction.

Calibration of a duplicate sensor array is needed to properly reduce temperature from millivolt data. Also, further analysis is necessary to insure that temperature measurements are not significantly effected by strain. One analysis method would be to test additional sensors oriented both radially and circumferencially to measure effects of strain components separately and possibly use a stiffened ring isolator around individual sensors to isolate temperature from strain completely.

A thermographic phosphor coating was used to visualize global temperature distribution. For these tests a dysprosium doped yttrium-vanadate rare-earth phosphor was used with a median powder size of 10 microns. The phosphor powder was suspended in a low-viscosity, high-temperature two-part epoxy binder and applied in a layer 
approximately 1-mil thick. This phosphor was chosen because of its high absortivity at its resonance absorption wavelength, requiring only a thin phosphor layer and a relatively high range of temperature sensitivity. The two-part epoxy binder (Duralco 4460) was chosen for its ultraviolet transparency and high temperature rating $\left(320^{\circ} \mathrm{C}\right.$ service temperature, tested $525^{\circ} \mathrm{C}$ for 3 minutes). The phosphor coating is excited with a 365 nanometer bandwidth filtered mercury arc lamp. At room temperature phosphor emission is low. Peak absorption shifts towards the $365 \mathrm{~nm}$ excitation with rising temperature because of resonance pathways in the crystal ligands, resulting in a maximum absorption and peak emission at $275^{\circ} \mathrm{C}$. Phosphor emission decreases past this temperature until fully quenched at $380^{\circ} \mathrm{C}$.

Phosphor coatings were applied to 1 -mil thick polyimide $60^{\circ}$ and $70^{\circ}$ half-angle test models and tested in the 31-inch Mach 10 air tunnel. Fluorescent fiducial points were also painted on the film surface using another fluorescent epoxy paint (blaze orange) to aid in later deflection measurements. In a test at $\mathrm{Re}_{1}=100 \mathrm{~K} / \mathrm{ft}$ the $60^{\circ}$ ballute (Fig. 14) shows a greater temperature increase around the outer edge of the ballute, becoming brighter at first then quenching at the end of the 3-second run. This indicates a maximum temperature near $380^{\circ} \mathrm{C}$ at the outer edge. At the same flow conditions $\left(\mathrm{Re}_{1}=\right.$ $100 \mathrm{~K} / \mathrm{ft}$, see Fig. 15) the $70^{\circ}$ ballute model is shown to increase in temperature more uniformly across the surface, reaching approximately full brightness $\left(380^{\circ} \mathrm{C}\right)$ at the end of the 3 -second run time. Tested at $\mathrm{Re}_{1}=200 \mathrm{~K} / \mathrm{ft}$ (Fig. 16) the $70^{\circ}$ ballute is shown to quench uniformly at the end of the 3 -second run indicating a uniform temperature near $380^{\circ} \mathrm{C}$.
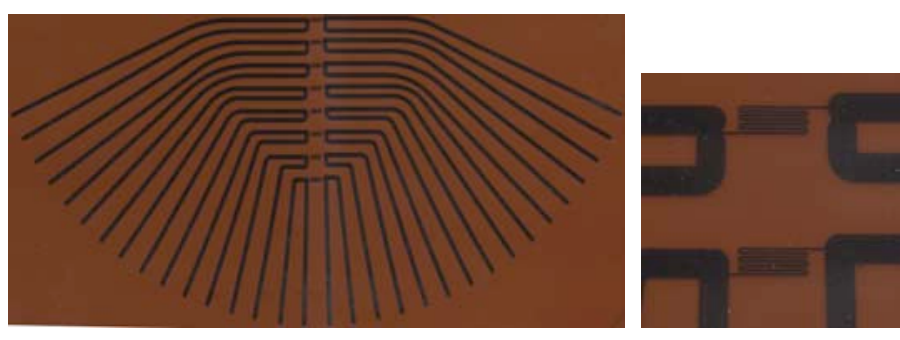

Figure 11. Laser-ablated thin-film resistance sensors on polyimide film.

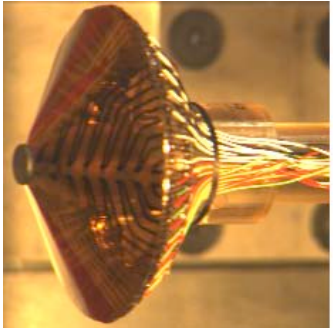

$60^{\circ}$ pre-run

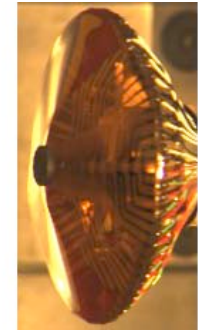

$70^{\circ}$ pre

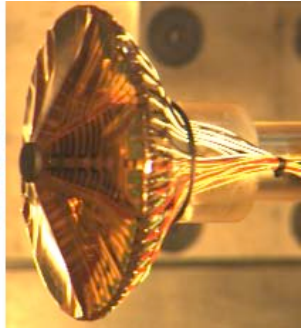

3-seconds in run
Figure 12. Instrumented ballute models in 31-Inch Mach 10 air tunnel.

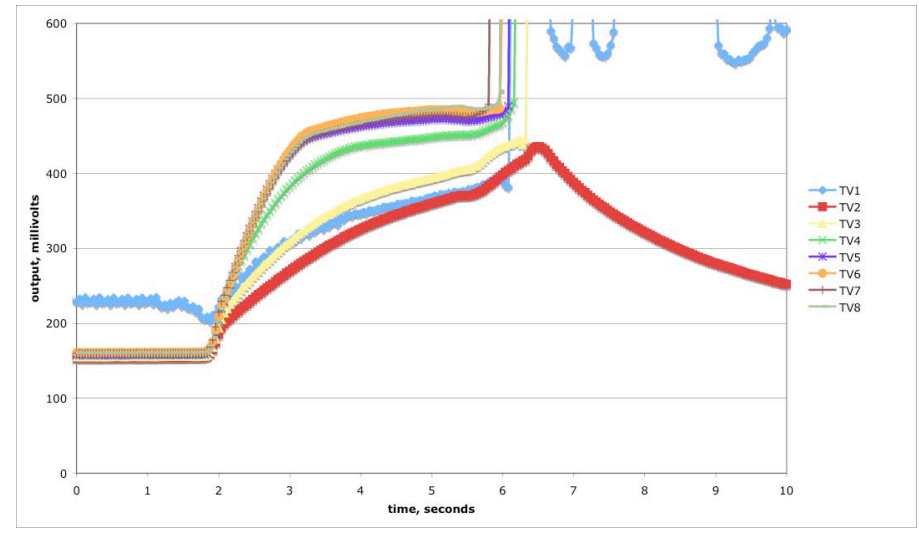

Figure 13. Millivolt output for $60^{\circ}$ half angle test model during test in 31-Inch Mach 10 air tunnel.

\section{Methods for Dynamic Free-Flight Stability Testing}

Aeroelastic deformations measured for $60^{\circ}$ half angle test models were obtained in test runs with only small fluctuations. These tests were relatively stable during the 10 second and 3 second runs in the hypersonic $\mathrm{CF}_{4}$ and Mach 10 air tunnels respectively. In comparison, a $45^{\circ}$ half angle model, 4-inch diameter with a 1-mil thick polyimide film, was completely unstable at both $\mathrm{Re}_{1}=100 \mathrm{~K} / \mathrm{ft}$ an $\mathrm{Re}_{1}=200 \mathrm{~K} / \mathrm{ft}$ in Mach 10 air. All of these results were obtained with a fixed base ring, in which the "toroidal" base section was only allowed to move axially with the flow. Further tests were designed to perform "free-flight" analysis of both trailing and afterbody-attached ballutes in the Mach 10 wind tunnel. 
To assemble "free-flight" test models, a lightweight flexible section had to be designed and fabricated. Figure 17 shows the components of the carbon-fiber mesh construction used in the fabrication. The lightweight carbon mesh fabric was press formed into molds along with a silicone stiffener. 4-inch full diameter with $3 / 4$-inch crosssection diameter toroids were fabricated to test afterbody-attached ballutes and 6-inch full diameter with 1-inch cross-section diameter toroids were fabricated to test tether-towed trailing ballutes. The tip or payload of the trailing-ballute test model was then mounted on the support sting with a ball and socket gimbal, and temporary wax supports are used to secure the base of the model as shown in Figure 18.

Wax supports were fabricated using a rapid prototyping 3-dimensional wax printer. Upon injection into the tunnel flow the wax supports break or melt away allowing the model to be inserted at the correct attitude without excessive buffeting before exposure. Wax supports wrap around the base as shown in Figure 18 for the afterbody-attached configuration, and act as interior spokes for the trailing configuration as shown in Figure 19.

Trailing ballute models were attached with three 0.010 -inch diameter nichrome tethers at $45^{\circ}$ half angles. The trailing ballute configuration also included a "stiff" model which is the lighter colored toroid shown on the left in Figure 19. For this stiff model a ceramic stiffener was used in place of the silicone in the molding process and did not deflect during the wind-tunnel run. The ceramic stiffened toroid mass was 18 grams. Masses of the silicone stiffened toriods were between 5 and 6 grams. 4-inch diameter toroids used in the afterbody-attached configuration were 4 grams.

All "free-flying" models were tested in the Mach 10 air tunnel at the lowest Reynolds number condition $\left(\mathrm{Re}_{1}=100 \mathrm{~K} / \mathrm{ft}\right)$. The stiff model photo shown in Figure 19 was taken after the model "flew" perfectly stable for 3-seconds.

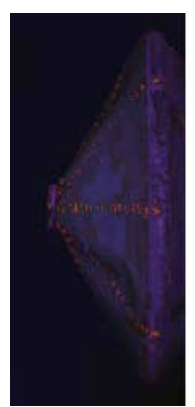

pre-run

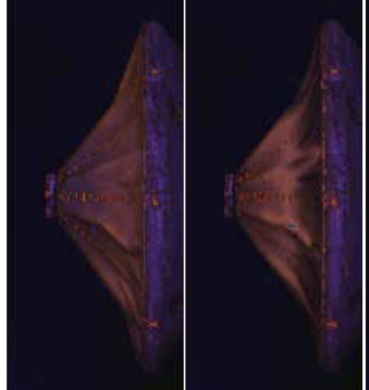

1.5 secs

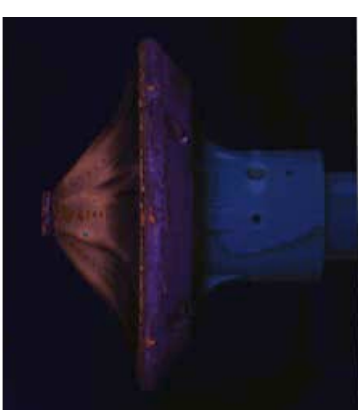

3 secs

Figure 14. Phosphor images for $60^{\circ}$ half angle attached ballute, $\operatorname{Re}_{1}=100 \mathrm{~K} / \mathrm{ft}, \mathrm{M}_{1}=10$.

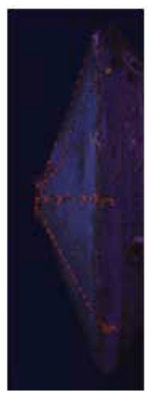

pre-run

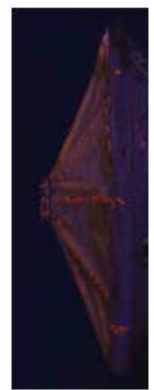

$\mathbf{t}=\mathbf{0}$ sec

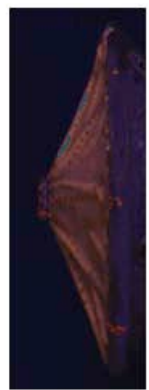

1.5 secs

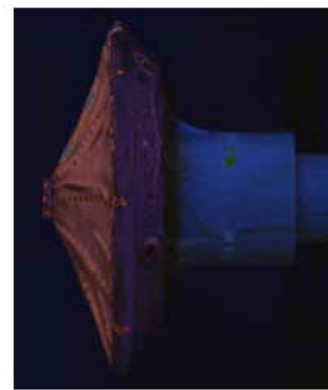

3 secs

Figure 15. Phosphor images for $70^{\circ}$ half angle attached ballute, $\operatorname{Re}_{1}=100 \mathrm{~K} / \mathrm{ft}, \mathrm{M}_{1}=10$.

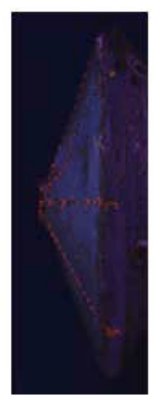

pre-run

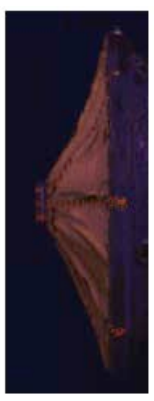

$\mathrm{t}=\mathbf{0} \sec$

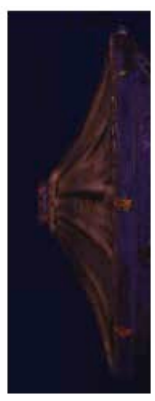

1.5 secs

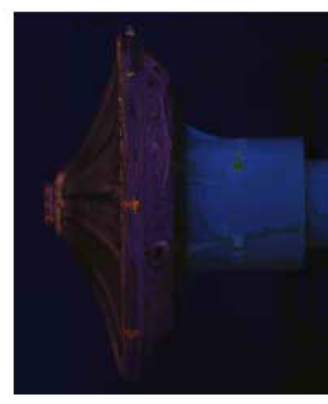

3 secs

Figure 16. Phosphor images for $70^{\circ}$ half angle attached ballute, $\operatorname{Re}_{1}=200 \mathrm{~K} / \mathrm{ft}, \mathrm{M}_{1}=10$. The remaining wax support was left in a pattern driven by the bow shock off the leading spacecraft. The flexible trailing ballutes, stiffened with silicone, all buckled and collapsed immediately upon insertion into the hypersonic flow. Stiffness measurements and buckling calculations were not made in advance for these particular test models as only a limited number of different stiffnesses were produced and all would have been tunnel tested regardless of predicted outcome.

Photos of the different stages in testing of a $70^{\circ}$ half angle afterbody attached ballute is shown in Figure 20 . A digital camera with a 0.030 second exposure time was used to take photos before the run and intervals during the run (18 frames per second). As shown in these intervals at $1 / 2,1$ and $1 \frac{1}{2}$ seconds the exposure time was much too long to capture the dynamics until $1 \frac{1}{2}$ seconds in which the model finally collapses into a stable configuration. 


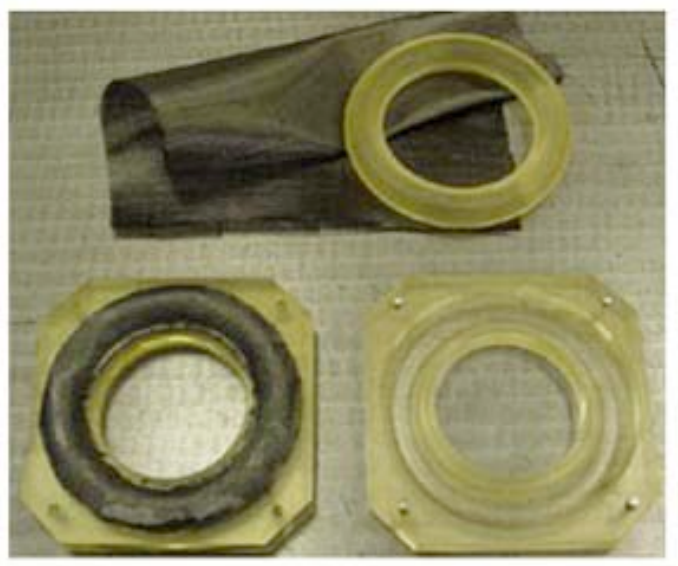

Figure 17. Carbon-fiber mesh.

From these tests it was shown that stiffness modeling would be difficult using the present methods, and that development of scaled inflatable models directly would probably be more effective.

\section{Validation Efforts}

Lower Mach numbers and higher Reynolds numbers relative to flight have been an issue in judging the value of hypersonic blow-down wind tunnels for validation or development of computational tools in predicting fluid-structure interactions. The thickness of a given ballute material also factors significantly into fluidstructure simulations but is not clearly represented in these parameters. Film thicknesses tested on scaled-down wind tunnel models have been typically the same as for fullscale. It is not practical to scale film thickness in wind-tunnel tests for a number of reasons. One is commercial availability or physical limitations in manufacturing and the other is the ability to handle and assemble such thin material. For a 1-mil (0.001 inch) film tested on a 25 millimeter wind-tunnel model, the thickness scale would be off by a factor of 300 relative to flight ( 7 meter vehicle with the same film thickness). For this reason only a flight test, or nearly full-scale model, can completely validate predictions of fluid structure interactions.

Present tests have proven useful in verifying tool development. Higher freestream Reynolds numbers produce stresses and deflections that are meaningful, or measurable in a wind tunnel test. The data is being used to verify the correct coupling of aerothermodynamic and structural codes by generating hypersonic continuum flow together with surface temperatures experienced in flight. Validation efforts using this data include a study to examine the accuracy of current analysis capability versus computational time with a loosely coupled fluid structure interaction procedure (Sasan Armand, AMA Inc.) and development of a more fully coupled analysis code with moving boundary capability (Reuben Rohrschneider, Ball Aerospace and Techn. Corp.). Comparisons have matched wrinkle patterns fairly well (wrinkles as shown in phosphor images Figs. 11-13) yet deformation profiles are predicted less than experiment, which is expected at this stage of code development due to un-modeled effects such as plasticity, creep and high-temperature material properties.

Validation efforts in other ground test facilities will also present difficulties in attempting to match fluid structure interactions to flight. Smaller test models used in the University of Virginia's open jet facility, to simulate transitional to free-molecular flow, mean even more difficulty in matching film thickness, or stiffness, to dynamic pressure. Tests in impulse facilities, such as the Large Energy Simulation (LENS) facilities at Calspan's University 

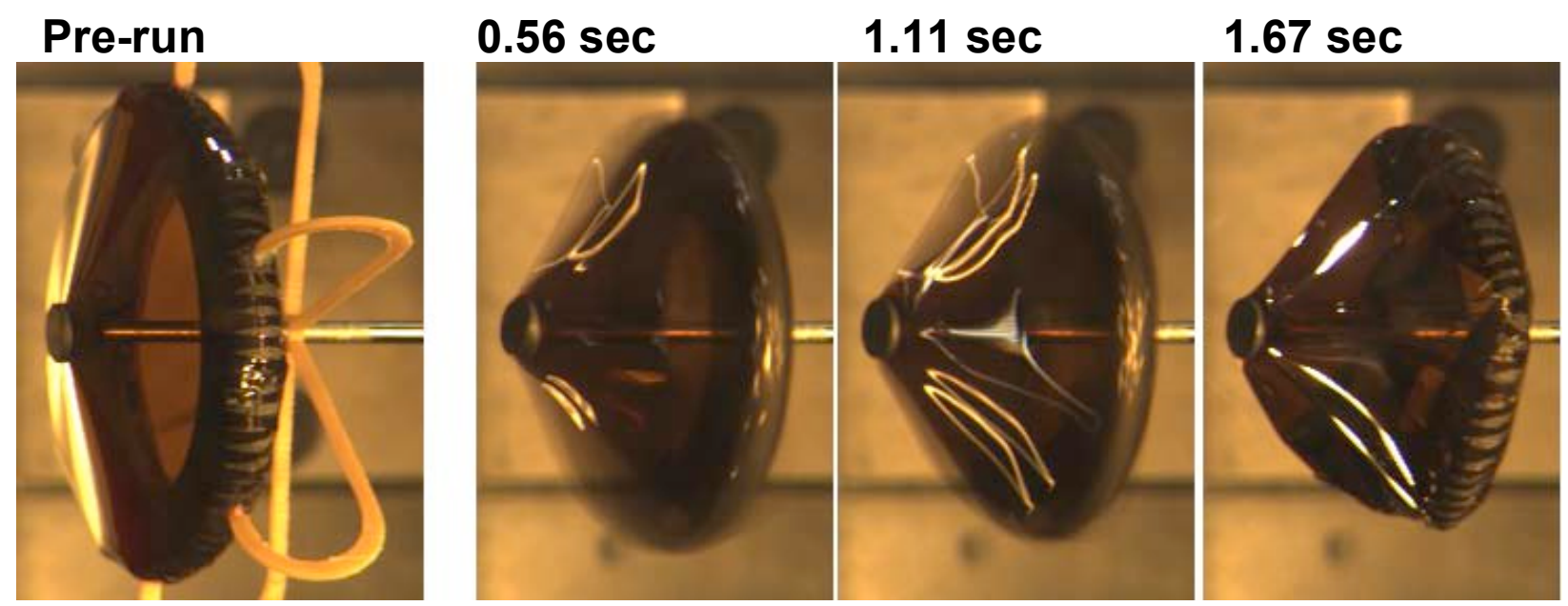

Figure 20. Free-flying $70^{\circ}$ half angle attached ballute, $R_{1}=200 \mathrm{~K} / \mathrm{ft}, M_{1}=10 .(0.030$ second exposure)

of Buffalo Research Center (CUBRC), are particularly useful in matching flight flow conditions but have much shorter run times ( 0.010 to 0.600 seconds) meaning that surface temperatures will not match flight or rise significantly during the test. One advantage of the LENS facility, however, is the possibility of testing a model ten times larger in scale.

\section{Summary}

As part of NASA's In-Space Propulsion technology development program for planetary aerocapture, advanced polymer film materials were evaluated for ultralight inflatable decelerators in a high-temperature, high-speed flow environment and experimental data for comparisons with fluid-structure interaction modeling tools were provided.

Free-flying testing techniques for dynamic stability measurements and methods for measuring polymer film temperature during testing were also developed.

\section{Acknowledgments}

The author would like to thank Pete Vasquez for his ingenuity and craftsmanship in the design, coordination and fabrication of the test articles, which made this work possible. Thanks are also extended to Tom Burns for his work in preserving the capabilities at Langley for laser cutting and etching the polymer materials and all those who were instrumental in the fabrication process, including but not limited to: Gary Wainwright, John Hopkins, Vince Cruz, Rick Hopson and Ralph Stephens. Finally, the author would like to thank those who were critical in making the tests successful, these would be the engineering technicians who handle, mount and run the tests in the hypersonic tunnels, particularly Henry Fitzgerald (Fitz) at the Mach 10 air tunnel and Cristal Kellam at the hypersonic $\mathrm{CF}_{4}$ tunnel.

\section{References}

${ }^{1}$ Hall, J. L., “A Review of Ballute Technology for Planetary Aerocapture,” IAA Paper L-1112, May 2000.

${ }^{2}$ Johnson, L., Baggett, R. M., Bonometti, J. A., Herrmann, M., James, B. F., and Montgomery, S. E., "NASA's In-Space Propulsion Technology Program: Overview and Update," AIAA Paper 2004-3851.

${ }^{3}$ Bartels, R. E., Moses, R. W., Scott, R. C., Templeton, J. D., Cheatwood, F. M., Gnoffo, P. A., and Buck, G. M., “A Proposed Role of Aeroelasticity in NASA's New Exploration Vision," International Forum on Aeroelasticity and Structural Dynamics, Paper IF-013, June 2005.

${ }^{4}$ Micol, J. R., "Hypersonic Aerodynamic/Aerothermodynamic Testing Capabilities at Langley Research Center: Aerothemodynamic Facilities Complex,” AIAA Paper 95-2107, 1995.

${ }^{5}$ Brown, G. and Richardson, R., "Minimum-Mass Design for Titan Aerocapture," AIAA Paper 2005-1637.

${ }^{6}$ Hollis, B. R., "Real-Gas Flow Properties for NASA Langley Research Center Aerothermodynamics Facilities Complex Wind Tunnels,” NASA CR 4755, September 1996. 
AIAA-2006-1319

American Institute of Aeronautics and Astronautics 